\title{
BIOMASS MODELING OF ALNUS NEPALENSIS D. DON AT JUVENILE STAGE
}

Shes Kanta Bhandari (Nepal)

Himlal Neupane (Nepal)

\section{ABSTRACT}

Juvenile stage plants contribute significant proportion of forest biomass and carbon depending on successional stage. Thus, the juvenile plants play a significant role in forest ecosystem and they cannot be neglected while estimating the total carbon stocks of the forest. Therefore this study was carried out develop juvenile biomass models. We measured diameter at $10 \mathrm{~cm}$ above ground level (D), total height $(H)$ and total biomass $(W)$ of Alnus nepalensis juveniles. We used least square regression technique to develop biomass models. The models were estimated using "library (minpack. Im)" in R. The estimated models were evaluated by using numerical fit statistics and graphical analyses. Among 136 different models tested, the model of the form: Wi= $\beta 0+\beta 1(D 2 H)$ with explanatory variable $\mathrm{D} 2 \mathrm{H}$ accounted for the largest proportion of biomass variations ( 2 2adj $=0.97$; $R M S E=42.34 g$; $A I C=406.8 .7$ ) for individual Alnus nepalensis juveniles, and showed relatively better graphical appearance and biological logic.

KEYWORDS: Alnus nepalensis, Biomass model, juvenile stage

\section{INTRODUCTION}

One or several predictor variables can generally be used to prepare biomass equations by using least square regression technique. Diameter, total height and wood density are the most widely used predictor variables, and these variables are used as a single or in combination with each other in the model (e.g. Chapagain et al., 2014; Chaturvedi et al., 2012; Subedi and Sharma, 2012; Basuki et al., 2009; Chave et al., 2005; Brown et al., 1989). Diameter is the easily and directly measurable variable therefore usually preferred for biomass modelling in spite of prediction accuracy of the developed models. The other variables are less frequently used in biomass modeling as they are difficult to measure in comparison to diameter (e.g. Kuyah et al., 2012; Ajit et al., 2011; Sharma, 2011; Singh et al., 2011; Telfer, 1969). Wood density may be considered as the best predictor variable as represents dry biomass or carbon amounts per unit volume of live wood and mechanical properties of plants (Navar, 2009a; Williamson \& Wiemann, 2010). To better describe the variation of biomass across geographical areas due to difference in site qualities, stand structures, and species composition, wood density is incorporated into biomass models (e.g. Alvarez et al., 2012; Baker et al., 


\section{Crossing the Border: International Journal of Interdisciplinary Studies}

2004; Basuki et al., 2009; Chaturvedi et al., 2010; Chaturvedi et al., 2012; Chave et al., 2005; Lindner and Sattler 2012; Nelson et al., 1999). However, because of the difficulties of getting information for this variable, biomass models with diameter alone or both diameter and height as explanatory variables are used. In this study only diameter and total height were used to develop bark biomass model.

Direct and indirect method can be used to estimate the individual tree and/or stand biomass. Cutting of plants and weighing of their parts to estimate biomass (direct method) is doubtlessly the most accurate method but it is very costly, time consuming and labor intensive (De Gier, 2003) and therefore it is commonly restricted to small areas and small sample size (Ketterings et al., 2001). The direct method is commonly used to validate the results of other less invasive and costly methods, such as estimation of biomass stock using non-invasive in-situ measurement and remote sensing (Clark et al., 2001). Allometric equations (Huxley $\&$ Teissier, 1936), yield the non-destructive and indirect estimate of biomass, are widely used for trees and forest biomass estimation (e.g. Chaturvedi et al., 2012; Subedi \& Sharma, 2012; Sharma, 2011; Hosoda \& Iehara, 2010). Morphometric variables such as plant diameter, height and density can easily be linked with dry matter content of the whole plant or its components via allometric equations (e.g. Subedi \& Sharma, 2012; Ajit et al., 2011; Basuki et al., 2009; Ketterings et al., 2001; Navar, 2009a).

A number of studies (e.g. Brown et al., 1989; Singh \& Singh, 1991; Ter-Mikaelian \& Korzukhin, 1997; Keith et al., 2000; Segura \& Kanninen, 2005; Zianis et al., 2005; Muukkonen, 2007; Navar, 2009b) have already indicated that the most of the studies on biomass have been undertaken on large sized forest species. A very limited biomass studies (e.g. Wagner \& Ter-Mikaelian, 1999; Geudens et al., 2004; Chaturvedi \& Raghubanshi, 2013; Chaturvedi et al., 2012; Chapagain et al., 2014) have been carried out for sapling and seedling hereafter termed as juveniles (defined as a plant $\geq 30 \mathrm{~cm}$ in height and $<10 \mathrm{~cm}$ in stem circumference at $10 \mathrm{~cm}$ above ground surface (Chaturvedi et al., 2012). Depending on the successional stages of any of the forest stands, juveniles may contribute about $5 \%$ of the total share of forest biomass (Francis, 2000). Thus, the juvenile plants play a significant role in forest ecosystem and they cannot be neglected while estimating the total carbon stocks of the forest. Biomass estimation of juvenile stage plants is also indispensable in management of forest and research such as assessment of net primary productivity (Telfer, 1969; Hitchcock, 1978), carbon sequestration potential (Reed et al., 1995), living and dead understory forest fuels (Agee, 1983), fiber production potential (Hitchcock, 1978), and formulation of silvicultural guidelines for desired species (Ter-Mikaelian and Parker, 2000).

Alnus nepalensis D. Don (family Betulaceae), commonly known as Alder, is a pioneer, deciduous and gregarious tree species of middle hills of Nepal. It is commonly distributed from 500m to $2700 \mathrm{~m}$ elevation. Particularly, at lower elevations it is characteristic of moist sites such as near rivers and in ravines but it is also a colonist of scaly and gravelly land exposed by landslips, and of abandoned cultivation (Jackson, 1994). This species is commonly used for fuelwood though does not have a good calorific value. Although it is not considered to be the best 
construction timber, it is very important in the middle hills for small timbers such as rafters, doors and window frames. It is also used for matches, papers and plywood (Jackson, 1994). The contribution of standing volumes of Alnus nepalensis to the total in the country has also been reported in DFRS (1999). Various natural and anthropogenic disturbances have been observed on the juvenile stage of forests in Nepal (Sapkota et al., 2009), but the intensity of disturbance is comparatively low in the study site due to community management regimes. A huge proportion of forest in the study site is in juvenile stage, and development of biomass models for them is very important from a biomass or carbon quantification point of view. A considerable underestimation of the total carbon in forest is realized due to unavailability of biomass model for juvenile stage plants. It is very essential to include juvenile stage plants in biomass studies because the role of juveniles in any forest is highly valuable from the carbon trade point of view. So far, to the authors' knowledge, no biomass studies have been conducted for juveniles of Alnus nepalensis in Nepal. Therefore, this work was carried out as a complementary work to reduce this gap, which led to the development of biomass models for the prediction of above-ground biomass for juveniles of Alnus nepalensis. It is anticipated that this study will be a valuable tool for forest managers, forest users and researchers and to contribute to the carbon trade programs of Nepal within the international community.

\section{MATERIALS AND METHODS}

\section{Study Site}

We carried out this study in Bhakarjung Community Forest of Dhikurpokhari village development committee (VDC) of Kaski district (Figure. 1) (280 06' N to $28036^{\prime} \mathrm{N}$ latitude and $83040^{\prime} \mathrm{E}$ to $84012^{\prime}$ E longitude) western Nepal. The total forest area in the district is 93649.85 ha.(46.43\%) out of which 65073.61 ha. (69.49\%) area is covered by Annapurna Conservation Area (ACA) and the remaining 28575.48 ha. (30.51\%) is managed by District Forest Office (DFO), Kaski. The altitudinal range of this district varies from 490 meters to 8091 meters from the sea level. Its average maximum temperature is $330 \mathrm{C}$ and average minimum temperature is $5.60 \mathrm{C}$ and the mean annual precipitation is $3068 \mathrm{~mm}$ to $3353.3 \mathrm{~mm}$. The forest has been managed as community forest. The forest is natural uneven and mixed in composition of Schima wallichii (Chilaune), Castanopsis indica (Dhale Katus), Alnus nepalensis (Utis), Qurcus semicarpifolia (Khasru), Rhododendron species (Laliguras), Bombax ceiba (Simal) and others.

\section{Sampling and Measurements}

The size variation of Alnus nepalensis in the study area was determined from forest management plan (operational plan). We selected individual juveniles subjectively in such a way that the selected juvenile would have adequately represented whole forest population, to represent wide variations of site quality, stand origin (natural or plantation), stand density, stand age, size and treatment (e.g. Adinugroho \& Sidiyasa, 2006; Dorado et al., 2006; Edwards Jr et al., 2006). This study followed the definition of juvenile as a plant having $\geq 30 \mathrm{~cm}$ in height and 


\section{Crossing the Border: International Journal of Interdisciplinary Studies}

$<10 \mathrm{~cm}$ in stem circumference at $10 \mathrm{~cm}$ above the ground surface (Chaturvedi et al., 2012), and measurements were made accordingly. We recorded measurement from 39 Alnus nepalensis juveniles. We avoided measurement from deformed, top broken, suppressed, leaning and wolf individuals. The diameter of each individual plant was measured with a vernier caliper at $10 \mathrm{~cm}$ above the ground level by following the rules of Chaturvedi and Khanna (2011). The selected individuals were felled from the base with a hand saw, and length (from base to top) of each juvenile was measured with a linear tape. The precisions of measurement for length and diameter of individuals are $1 \mathrm{~cm}$ and $1 \mathrm{~mm}$, respectively. Then leaves and branches from each of the felled individuals were separated. Each component (stem, leaves, and branch) was weighed in situ immediately after felling and recorded at a precision of $0.1 \mathrm{~g}$. Samples of the stem, leaf and branch were prepared, and carried to the laboratory for drying. Drying was carried out in an oven at $1050 \mathrm{C}$ until a constant weight was achieved. The weight of the samples was first recorded after 24 hours and then repeated at the interval of 8 hours. The dry weight of each component (stem, leaf and branch) of the individual juvenile was determined using the dry to fresh weight ratio estimated from the samples. The volume of stem was estimated with using xylometric method (Chaturvedi \& Khanna, 2011). Then wood density of stem was determined by using following formula (Chave et al., 2006):

$$
\text { Wood density }(\rho)=\frac{\text { Oven dry weight of sample }}{\text { Fresh volume of sample }}
$$

A summary of the modeling data is presented in Table 1.

\section{Modeling approach}

Biomass of the whole plant or its parts can be modeled as a function of diameter alone (e.g. Ajit et al., 2011; Kuyah et al., 2012; Sharma, 2011; Singh et al., 2011) or diameter or height combined together (e.g. Chapagain et al., 2014; Subedi \& Sharma, 2012; Hosoda \& Iehara, 2010; Rizvi et al., 2008; Ketterings et al., 2001; Senelwa \& Sims, 1997), or in combination of diameter, height and wood density (e.g. Chapagain et al., 2014; Alvarez et al., 2012; Chaturvedi et al., 2012; Basuki et al., 2009; Chave et al., 2005). In this study we used all three variables singly or in combination to describe the above ground juvenile biomass of Alnus nepalensis. These variables are diameter alone (D, $\left.\mathrm{D}^{2}\right)$ and diameter and height combined $\left(\mathrm{DH}, \mathrm{D}^{2} \mathrm{H}\right)$, wood density and diameter combined $\left(\rho \mathrm{D}, \rho \mathrm{D}^{2}\right)$ and wood density, diameter and height combined $\left(\rho \mathrm{DH}, \rho \mathrm{D}^{2} \mathrm{H}\right)$. We developed bark biomass models by using each of the eight explanatory variables alternative, and designated first model category for a model with $\mathrm{D}$ alone, second model category for a model with $\mathrm{D}^{2}$ and third model category for a model with $\mathrm{DH}$ and so on resulting in eight different model categories in total. We, hereafter, have termed them as first model category, second model category, and so on, and thus each model category contains 17 alternative models (i.e. $8 \times 17=136$ alternative models, see Table: 2 for details). 
We used least square technique, which is commonly used to develop biomass models for individual trees or their parts. Among several mathematical models tested, only converged models (with significant parameter estimates) for each of the explanatory variable alternatives are considered for analysis. The models were estimated using "library(minpack.lm)" package in which $\operatorname{lm}$ (for linear models), nls and nlsLM (for non linear models) commands in R (R Core Team, 2012). The estimated models were evaluated using various criteria such as (1) significance of parameter estimates, (2) root mean squared error (RMSE), which is also known as a measure of model's precision, (3) adjusted coefficient of determination (R2adj) (Montgomery et al., 2001), (4) Akaike information criterion (AIC), and this is known as one of the most reliable statistical criteria to compare the estimated models (Akaike, 1972; Burnham \& Anderson, 2002), (6) Graphs of residuals, scaled and quantile-quantile (q-q) plot of estimated models were also examined to check whether models had theoretical basis and biological logics (Alder, 1995; Zeide, 1993; Goelz \& Burk, 1992). Unless otherwise specified, we used $0.05(\alpha=5 \%)$ level of significance in our analyses.

\section{RESULTS AND DISCUSSION}

Parameter estimates of 108 models out of 136 models ( $8^{\star} 17=136$ models or 18 models in each model category, see Table 2 for details) were significant. This shows that most of the models (108 significant models) tested in this study are appropriate to the data. There was still a significant portion of residuals variation left unexplained $(\mathrm{RMSE}=42 \mathrm{~g}$ ) though our models showed promising fits to the given data. It is obvious that any of the mathematical models cannot perfectly describe the data of all survey everywhere (Hasenauer \& Monserud, 1997; Montgomery et al., 2001; Ratkowsky, 1990). Therefore, the biometricians need to test several candidate models of various mathematical forms (linear, power, parabolic, exponential, and asymptotic) to their data which could offer good chance to get more suitable model to the data (e.g. Ajit et al., 2011; Fang \& Bailey, 1998; Huang et al., 1992; Ratkowsky, 1990; Rizvi et al., 2008; Sharma et al., 2011). Among 136 alternative models, fit statistics and parameter estimates of only best model in each model category are listed in Table 3. M9 from fourth model category, M6 from eighth model category and M2 from first model category showed the best fits (smallest RMSE, AIC and largest R2adj) among the models. The first model M1, the most versatile equation to develop biomass model (Sharma, 2011; Miksys et al., 2007; Ter-Mikaelian \& Korzukhin, 1997), appeared in the tenth, sixth, fourth, fourth, ninth, first, first and second rank within the models from the first, second, third, fourth, fifth, sixth, seventh and eighth model category, respectively. From the evaluation of fit statistics, M9 seems to be the most accurate and precise among the fourth model category and followed by the models M6 of the eighth model category, M2 of first model category, M15 of second model category, M6 of fifth model category, M14 of third model category, M1 of seventh model category and M1 of sixth model category. Graphs of model residuals, scaled and normal Q-Q were also examined.

The unstandardized residuals against the fitted values with a smooth superimposed curve for model M9 from model category fourth, model M6 from model 


\section{Crossing the Border: International Journal of Interdisciplinary Studies}

category eighth and model M2 from model category first is shown in fig 2. Here we are looking for evidence of curvature and outliers. The graph of M9 from category fourth shows negligible curvature and outliers in comparison to remaining two models. Absence of curvature in M9 category fourth suggests us the absence of local bias in the model.

The fig 3 shows the square root of the standardized residuals against fitted value along with smooth line. Departure from horizontal lines signify heteroskedasticity, contradicting the model assumption " $\varepsilon i$ have constant variance", (Robinson and Hamann, 2011) but the model M9 from category fourth shows the less heteroskedasticity than other models. Similarly, fig 4 shows a q-q plot of the standardized residuals against the normal distribution. Here the ideal plot is a straight line, although modest departures from straightness are often acceptable (due to large-sample theory). Departures from a straight line in this plot may indicate non-normality of the residuals or non-constant variance, or both (Robinson and Hamann, 2011). But in our analysis, we found all the points are in a reasonably straight line which indicates the normal distribution of residuals.

Overall performance of two independent variables $\mathrm{D}$ and $\mathrm{H}$ in the form of the $\mathrm{D}^{2} \mathrm{H}$ seems to be much promising in case of model M9 from model category fourth because it showed best fits and comparatively smaller residual deviations and better biological logics. We selected M9 from fourth model category for the prediction of juvenile biomass of Alnus nepalensis. The prediction of juvenile biomass for individual Alnus nepalensis should be made with following equation:

$$
\hat{\mathrm{Wi}}=57.75+12.07\left(\mathrm{Di}^{2} \mathrm{Hi}\right)
$$

Most of the allometric equations used in this study (Table 2) have also been used to develop several biomass models in natural resource management studies. The linear models we used in this study better described the data than their non-linear counterparts, because our data cover a wide range of Alnus nepalensis plant sizes (Table 1). As the data which we used to develop biomass models were not sufficiently described by most commonly used explanatory variable diameter alone like in other studies (eg. Chapagain et al., 2014; Subedi \& Sharma, 2012; Ketterings et al., 2001; Senelwa \& Sims, 1997), inclusion of other variable (height) as additional explanatory variable improved the model fits significantly. Any of three best models (Table 3) can be applied for prediction of juvenile biomass of each Alnus nepalensis with a reasonable accuracy. But these models should not be applied beyond the observed data ranges (Table 1) and stand conditions different from the basis of this study.

For model application, the first best model needs diameter at above $10 \mathrm{~cm}$ from ground and total height, while the second best model (density dependent model) requires density, diameter at above $10 \mathrm{~cm}$ from ground and total height. Thus, the density dependent model requires an extra variable (i.e. species-specific wood density) whose access is difficult and costly. But the third best model requires diameter at above $10 \mathrm{~cm}$ from ground only. Though the model based on diameter alone is easy to use, its accuracy and reliability is less than those requiring density, diameter and height. In practice also biomass models based on diameter and height are commonly developed (e.g. Chapagain et al., 2014; Subedi 
\& Sharma, 2012; Hosoda \& Iehara, 2010; Rizvi et al., 2008; Wang, 2006; Ketterings et al., 2001; Senelwa \& Sims, 1997; Vanclay, 1994).

Model that depends on fewer and easily accessible independent variables is usually favored, and the inclusion of additional variables into the model results in over-parameterization and biased estimation (Montgomery et al., 2001; Vanclay, 1994). The biomass models which depends on density (e.g. Alvarez et al., 2012; Chaturvedi \& Raghubanshi, 2013; Chaturvedi et al., 2012; Lindner and Sattler, 2012; Basuki et al., 2009; Navar, 2009a; Chave et al., 2005; Nelson et al., 1999) are expected to better describe that varies with site qualities, ages, species, stand structure, species composition, origin and so on. Density dependent models and the models depending on diameter and height are definitely more accurate and precise and have wider scope than the models with diameter alone as the former models would be more generalized ones. In practice, the height measurement is comparatively difficult, costlier and less accurate than diameter, and therefore the model based on diameter only is most preferred. In spite of its poor performance, a model M2 (third best model) depending on D only can also be used when other explanatory variables (density and total height) are not available.

A number of sampled juveniles used in this study is fairly sufficient as they adequately represent all possible site qualities, size class, and stand conditions for plant population of Alnus nepalensis in the study site. Size of sample used in this study is also larger than that used in other biomass studies (Chaturvedi et al., 2012; Sharma, 2011; Basuki et al., 2009). Similar to other various biomass estimation and modeling research studies (e.g.Chapagain et al., 2014; Chaturvedi et al., 2012; Subedi \& Sharma, 2012; Sharma, 2011; Lambert et al., 2005), we also used destructive sampling that requires much time and financial resources, and therefore, rarely applied for large scale sample size and large geographical area. Biomass modelling from relatively small number of sampled individuals would be sufficient when they were properly representative to all possible sizes, sites and stand conditions (e.g. Chapagain et al., 2014; Subedi \& Sharma, 2012; Sharma, 2011; Zianis et al., 2005; Bartelink, 1996). We could not validate the models due to lack of independent data, but further evaluations will made when the independent data are available in the future.

\section{CONCLUSION}

Among 136 candidate models tested, a model (M9) with diameter and total height as independent variables in the form of $\mathrm{D} 2 \mathrm{H}$ best described our data (smallest RMSE and AIC, and largest R2adj). This model explained $>97 \%$ juvenile biomass of Alnus nepalensis with $\mathrm{RMSE}=42.34 \mathrm{~g}$ and $\mathrm{AIC}=406.8$. This model is, therefore, recommended for prediction of juvenile biomass of Alnus nepalensis. Application of this model is recommended to restrict to the site, size and stand condition similar to the basis of this study because this model is explicitly site-specific. Further research studies for validation, verification and re-calibration of our models with new data from wider range of site, size and stand conditions of Alnus nepalensis are recommended. 


\section{Crossing the Border: International Journal of Interdisciplinary Studies}

\section{REFERENCES}

Adinugroho, W.C.D., \& Sidiyasa, K. (2006). Biomass estimation model of above-ground mahogany(Swietenia macrophylla) tree. J Penel Hut Konser Alam, 3 (1), 103-117.

Agee, J.K. (1983). Fule weights of understory-grown confiers in souther Oregon. Can J For Res, 13 (4), 648-656.

Ajit Das, D.K., Chaturvedi,O.P., Jabeend, N., \& Dhyani, S.K. (2011). Predictive models for dry weight estimation of above and below ground biomass components of Populus deltoides in India: Development and comparative diagnosis. Biomass Bioenerg, 35(3), 1145-1152.

Akaike, H. (1972). A new look at statistical model identification, p. 716-722 in IEEE trans, on automatic control, $\mathrm{Au}-19$.

Alder, D. (1995). Growth modelling for mixed tropical forests. Tropical forestry paper 30, Nuffield Press, Oxon, 231 p.

Alvarez, E., Duque, A., Saldarriaga, J., Cabrera, K., \& Salas, G.D. (2012). Tree aboveground biomass allometries for carbon stocks estimation in the natural forests of Colombia. Forest Ecology and Management, 267, 297-308.

Baker, T.R., Phillips, O.L., Malhi, Y., Almeida, S., Arroyo, L., Fiore, A., Erwin, T., Killeen, T.J., Laurance, S.G., Laurance, W.F., Lewis, S.L. et al. (2004). Variation in wood density determines spatial patterns in Amazonian forest biomass. Glob Change Bio, 10 (5), 545-562.

Bartelink, H.H. (1996). Allometric relationships on biomass and needle area of Douglasfir. Forest Ecology and Management, 86 (1-3), 193-203.

Basuki, T.M., van Laake, P.E., Skidmore, A.K., \& Hussin, Y.A. (2009). Allometric equations for estimating the above-ground biomass in tropical lowland Dipterocarp forests. Forest Ecology and Management, 257(8), 1684-1694.

Brown, S. (1997). Estimating biomass and biomass change of tropical forests: a primer. FAO Forestry paper 134. FAO, Rome.

Brown, S., Gillespie, A.J.R., \& Lugo, A.E. (1989). Biomass estimation for tropical forests with applications to forest inventory data. Forest Science, 35(4), 881-902.

Burnham, K.P. \& Anderson, D.R. (2002). Model selection and inference: A practical information theoretic approach. Springer-Verlag, New York.

Chapagain, T., Sharma, R.P. \& Bhandari, S.K. (2014). Modelling above-ground biomass for three tropical tree species at their juvenile stage. Forest Science and Technology, 1-10, DOI:10.1080/21580103.2013.834277

Chaturvedi, A.N., \& Khanna, L.S. (2011). Forest mensuration and biometry 5th Edition. Khanna Bandhu, Dheradun, India.

Chaturvedi, R.K., Raghubanshi, A.S., \& Singh, J.S. (2010). Non-destructive estimation of tree biomass by using wood specific gravity in the estimator. Nat Acad Sci LettersIndia, 33(5-6), 133-138.

Chaturvedi, R.K., \& Raghubanshi, A.S. (2013). Aboveground biomass estimation of small diameter woody species of tropical dry forest. New Forests, 44(4),509-519.

Chaturvedi, R.K., Raghubanshi, A.S., \& Singh, J.S. (2012). Biomass estimation of dry tropical woody species at juvenile stage. The scientific world journal. 1-5 (doi:10.1100/2012/790219).

Chave, J., Andalo,C., Brown, S., Cairns, M.A., \& Chambers, J.Q. (2005). Tree allometry and improved estimation of carbon stocks and balance in tropical forests. Oecologia. 145 (1):187-99.

Chave. J., Muller-Landau, H.C., Baker, T.R., Easdale, T.A., \& Ter Steege, H., Webb, C.O. (2006). Regional and phylogenetic variation of wood density across neotropical tree species. Ecol Appl, 16(6), 2356-2367. 
Clark, D.A., Brown, S., Kicklighter, D.W., Chambers, J.Q., Thomlinson, J.R., \& Ni, J. (2001). Measuring net primary production in forests: Concepts and field methods. Ecol Appl. 11(2):356-370.

De Gier, A. (2003). A new approach to woody biomass assessment in woodlands and shrublands. P. 161-198 in Geoinfor trop ecosyst, Roy, P.S. (eds.).

DFRS, (1999). Forest Resources of Nepal. Department of Forest Research and Survey. Ministry of Forest and Soil Conservation, HMGN/ FINIDA, Report No.74, 33 p. (p + Appendices).

Dorado, F.C., Dieguez-Aranda, U., Anta, M.B., Rodriguez, M.S., \& von Gadow, K. (2006). A generalized height-diameter model including random components for radiata pine plantations in northwestern Spain. Forest Ecology and Management, 229 (1-3), 202-213.

Edwards, Jr T.C., Cutler, D.R., Zimmermann, N.E., Geiser, L., \& Moisen, G.G. (2006). Effects of sample survey design on the accuracy of classification tree models in species distribution models. Ecol Modell, 199 (2), 132-141.

Fang, Z.X., Bailey, R.L. (1998). Height-diameter models for tropical forests on Hainan Island in southern China. Forest Ecology and Management, 110 (1-3), 315-327.

Francis, J.K. (2000). Estimating biomass and carbon content of saplings in Puerto Rican secondary forests. Caribb J Sci, 36 (3-4), 346-350.

Goelz, J.C.G., \& Burk, T.E. (1992). Development of a well-behaved site index equationJack pine in North central Ontario. Can J For Res, 22 (6), 776-84.

Geudens, G., Staelens, J., Kint, V., Goris, R., \& Lust, N. (2004). Allometric biomass equations for Scots pine (Pinus sylvestris L.) seedlings during the first years of establishment in dense natural regeneration. Ann For Sci, 61(7),653-659.

Hasenauer, H., \& Monserud, R.A. (1997). Biased predictions for tree height increment models developed from smoothed 'data'. Ecol Modell, 98 (1): 13-22.

Hitchcock, H.C. (1978). Above-ground tree weight equations for hardwood seedling and sapling. Tappi, 61(10),119-120.

Hosoda, K., \& Iehara, T. (2010). Abovegroud biomass equations for individual trees of Cryptomeria japonica, Chamaecyparis obtusa and Larix kaempferi in Japan. J For Res, 15: 299-306.

Huang, S., Titus, S.J., \& Wiens, D.P. (1992). Comparison of non-linear height-diameter functions for major Alberta tree species. Can J For Res, 22 (9), 1297-1304.

Huxley, J.S., \& Teissier, G. (1936). Terminology of relative growth. Nature, 137(3471), 780-781.

Jackson, J.K. (1994). Manual of afforestation in Nepal. Kathmandu: Forest research and survey center. Second edition. 824p.

Keith, H., Barrett, D., \& Keena, R. (2000). Review of allometric relationships for estimating woody biomass for New South Wales, the Australian Capital Territory, Victoria, Tasmania, and South Australia. National Carbon Accounting System Technical Report 5B. Australian Greenhouse Office, Canberra, 114 p.

Ketterings, Q.M., Coe, R., van Noordwijk, M., Ambagau, Y., \& Palm, C.A. (2001). Reducing uncertainty in the use of allometric biomass equations for predicting aboveground tree biomass in mixed secondary forests. Forest Ecology and Management, 146 (1-3), 199-209

Kuyah, S., Dietz, J., Muthuri, C., Jamnadass, R., Mwangi, P. et al. (2012). Allometric equations for estimating biomass in agricultural landscapes: I. Aboveground biomass. Agri Ecoyst En, 158, 216-224.

Lambert, M.C., Ung, C.H., \& Raulier, F. (2005). Canadian national tree abovegournd biomass equations. Can J For Res, 35, 1996 -2018.

Lindner, A. \& Sattler, D. (2012). Biomass estimations in forests of different disturbance 


\section{Crossing the Border: International Journal of Interdisciplinary Studies}

history in the Atlantic Forest of Rio de Janeiro, Brazil. New Forests, 43 (3), 287-301.

Miksys, V., Varnagiryte-Kabasinskiene, I., Stupak, I., Kestutis, A., Kukkola, M., \& Wo' jcik, J. (2007). Above-ground biomass functions for Scots pine in Lithuania. Biomass Bioener, 31(10), 685-92.

Montgomery, D.C., Peck, E.A., \& Vining, G.G. (2001). Introduction to linear regression analysis. New York, Wiley, $641 \mathrm{p}$.

Muukkonen, P. (2007). Generalized allometric volume and biomass equations for some tree species in Europe. Eur J For Res, 126 (2), 157-166.

Navar, J. (2009a). Allometric equations for tree species and carbon stocks for forests of northwestern Mexico. Forest Ecology and Management, 257 (2), 427-434.

Navar, J.( 2009b). Biomass component equations for Latin American species and groups of species. Ann For Sci, 66(2), (doi: 10.1051/forest/2009001)

Nelson, B.W., Mesquita, R., Pereira, J.L.G., de Souza, S.G.A., Batista, G.T. and Couto, L.B. (1999). Allometric regressions for improved estimate of secondary forest biomass in the central Amazon. Forest Ecology and Management, 117 (1-3), 149-167.

Ratkowsky, D.A. (1990). Handbook of non-linear regression. Marcel Dekker, Inc. 127: 241 p.

R Core Team, (2012.) R: A language and environment for statistical computing. R Foundation for Statistical Computing, Vienna, Austria. ISBN 3-900051-07-0, URL http:// www.R-project.org/.

Reed, D.D., Mroz, G.D., Liechty, H.O., Jones, E.A., Cattelino, P.J., Balster, N.J., Zhang, Y., et al. (1995). Above-ground and belowground biomass of precompetitive red pine in northern Michigan. Can J For Res, 25(7),1064-1069.

Rizvi, R. H., Gupta, V.K., Ajit. (2008). Comparison of various linear and non-linear functions for estimating biomass and volume of Dalbergia sissoo grown under rainfed conditions. Indian J Agr Sci, 78 (2), 138-141.

Robinson, A.P., \& Hamann, J.D. (2011). Forest analytics with R, an introduction. New York: Springer. 355p.

Sapkota, I.P., Tigabu, M., \& Oden, P.C. (2009). Spatial distribution, advanced regeneration and stand structure of Nepalese Sal (Shorea robusta) forests subject to disturbances of different intensities. For Ecol Manage, 257(9), 1966- 1975.

Segura, M., \& Kanninen, M. (2005). Allometric models for tree volume and total aboveground biomass in a tropical humid forest in Costa Rica. Biotropica, 37(1), $2-8$.

Senelwa, K., \& Sims, R.E.H. (1997). Tree biomass equations for short rotation eucalypts grown in New Zealand. Biomass Bioenerg, 13(3), 133-140.

Sharma, R.P. (2006). Modelling growing space requirement for Alnus nepalensis D. Don. in Nepal. Banko Janakari, 16 (2), 30-36.

Sharma, R.P. (2011). Allometric models for total-tree and component tree biomass of Alnus nepalensis D. Don in Nepal. Indian Forester, 137(12),1386-1390.

Sharma, R.P., Brunner, A., Eid, T., \& Oyen, B-H. (2011). Modelling dominant height growth from national forest inventory individual tree data with short time series and large age errors. For Ecol Manage, 262 (12), 2162-2175.

Singh, L., \& Singh, J.S. (1991). Species structure, dry-matter dynamics and carbon flux of dry tropical forest in India. Ann Bot, 68 (6), 263-273.

Singh, V., Tewari, A., Kushwaha, S.P.S. \& Dadhwal, V.K. (2011). Formulating allometric equations for estimating biomass and carbon stock in small diameter trees. Forest Ecology and Management, 261(11), 1945-1949.

Spurr, S. H. (1952). Forest inventory. Ronald press, New York. 476 p.

Subedi, M., \& Sharma, R.P. (2012). Allometric biomass models for bark of Cinnamomum 
tamala in mid-hill of Nepal. Biomass and Energy. 47, 44-49.

Telfer, E.S. (1969). Weight-diameter relationship for 22 woody plant species. Can J Bot, 47(12), 5171851.

Ter-Mikaelian, M.T., \& Korzukhin, M.D. (1997). Biomass equations for sixty five north American tree species. Forest Ecology and Management, 97(1),1-24.

Ter-Mikaelian, M.T., \& Parker, W.C. (2000). Estimating biomass of white spruce seedlings with vertical photo imagery. New Forests, 20(2), 145-162.

Vanclay, J. K. (1994). Modelling forest growth and yield. Applications to mixed tropical forests. CAB International, Oxon, UK. 312 p.

Wagner, R.G., \& Ter-Mikaelian, M.T. (1999). Comparison of biomass component equations for four species of northern coniferous tree seedlings. Ann For Sci, 56(3),193199.

Wang, C.K. (2006). Biomass allometric equations for 10 co-occurring tree 529 species in Chinese temperate forests. Forest Ecology and Management, 222 (1-3), 9-16.

Williamson, G.B., \& Wiemann, M.C. (2010). Age-dependent radial increases in wood specific gravity of tropical pioneers in Costa Rica. Biotropica, 42(5), 590-597.

Zeide, B. (1993). Analysis of growth equations. Forest Science, 39(3), 594-616.

Zianis, D., Muukkonen, P., Makipa, R. \& Mencuccini, M. (2005). Biomass and stem volume equations for tree species in Europe. Silva Fenn. Monogr. 4, 63 p.

\section{APPENDIX I: TABLES}

Table 1: Summary statistics of data

\begin{tabular}{|c|c|c|}
\hline Diameter class & Variables & Mean \pm std. (range) \\
\hline \multirow[t]{5}{*}{$1-2$} & Diameter $(\mathrm{cm})$ & $1.37 \pm 0.28(1-1.98)$ \\
\hline & Height (m) & $2.06 \pm 0.61(1.15-3.2)$ \\
\hline & Wood density (gcm-3) & $0.29 \pm 0.02(0.24-0.33)$ \\
\hline & Biomass (g) & $108.23 \pm 46.27(31-227.77)$ \\
\hline & Number & 18 \\
\hline \multirow[t]{5}{*}{$2-3$} & Diameter $(\mathrm{cm})$ & $2.41 \pm 0.31(2-2.96)$ \\
\hline & Height $(\mathrm{m})$ & $3.49 \pm 0.69(2.8-5.05)$ \\
\hline & Wood density (gcm-3) & $0.30 \pm 0.03(0.26-0.37)$ \\
\hline & Biomass (g) & $306.38 \pm 102.93(168.1-472.46)$ \\
\hline & Number & 12 \\
\hline \multirow[t]{5}{*}{$3-4$} & Diameter $(\mathrm{cm})$ & $3.27 \pm 0.22(3.05-3.17)$ \\
\hline & Height $(\mathrm{m})$ & $4.69 \pm 0.82(3.55-5.9)$ \\
\hline & Wood density (gcm-3) & $0.33 \pm 0.05(0.27-0.44)$ \\
\hline & Biomass (g) & $691.97 \pm 164.85(490.2-942.89)$ \\
\hline & Number & 9 \\
\hline \multirow[t]{5}{*}{ Overall } & Diameter $(\mathrm{cm})$ & $2.13 \pm 0.82(1-3.17)$ \\
\hline & Height $(\mathrm{m})$ & $3.11 \pm 1.26(1.15-5.9)$ \\
\hline & Wood density (gcm-3) & $0.3 \pm 0.03(0.24-0.44)$ \\
\hline & Biomass (g) & $303.91 \pm 252.07(31-942.89)$ \\
\hline & Number & 39 \\
\hline
\end{tabular}


Crossing the Border: International Journal of Interdisciplinary Studies

Table 2: Candidate models considered

\begin{tabular}{|c|c|c|}
\hline Specification & Model form & References \\
\hline M1 & $\mathrm{Yi}=\beta 0 \mathrm{Xi} \beta 1+\varepsilon \mathrm{i}$ & Huxley and Teissier (1936) \\
\hline M2 & $Y i=\beta 0 \exp (\beta 1 X i)+\varepsilon i$ & Rizvi et al. (2008) \\
\hline M3 & $\mathrm{Yi}=\beta 0 \exp (-\beta 1 / \mathrm{Xi})+\varepsilon \mathrm{i}$ & Schumacher (1939) \\
\hline M4 & $\mathrm{Yi}=\beta 0[1-\exp (-\beta 1 \mathrm{Xi})] 3+\varepsilon \mathrm{i}$ & Bertalanffy (1949) \\
\hline M5 & $\mathrm{Yi}=\beta 0 \exp (\beta 1 / \mathrm{Xi})+\varepsilon \mathrm{i}$ & Modified after Schumacher (1939) \\
\hline M6 & $\mathrm{Yi}=\beta 0+\beta 1 \mathrm{Xi}+\beta 2 \mathrm{Xi} 2+\varepsilon \mathrm{i}$ & Brown (1997) \\
\hline M7 & $\mathrm{Yi}=\beta 0+\beta 1 \mathrm{Xi} 2+\varepsilon \mathrm{i}$ & Sharma (2011) \\
\hline M8 & $\mathrm{Yi}=\beta 0+\beta 1 / \mathrm{Xi}+\beta 2 \mathrm{Xi} 2 \varepsilon \mathrm{i}$ & Sharma (2011) \\
\hline M9 & $Y i=\beta 0+\beta 1 X i+\varepsilon i$ & Spurr(1952) \\
\hline M10 & $\mathrm{Yi}=\beta 0+\mathrm{Xi} \beta 1+\varepsilon \mathrm{i}$ & Subedi and Sharma (2012) \\
\hline M11 & $\mathrm{Yi}=\mathrm{Xi} /(\beta 0+\beta 1 \mathrm{Xi})+\varepsilon \mathrm{i}$ & Hosoda and Iehara (2010) \\
\hline M12 & $\mathrm{Yi}=\mathrm{Xi} 2 /(\beta 0+\beta 1 \mathrm{Xi})+\varepsilon \mathrm{i}$ & Modified after Hosoda and Iehara (2010) \\
\hline M13 & $\mathrm{Yi}=\mathrm{Xi} 2 /(\beta 0+\beta 1 \mathrm{Xi} 2)+\varepsilon \mathrm{i}$ & Modified after Hosoda and Iehara (2010) \\
\hline M14 & $\mathrm{Yi}=\beta 0+\beta 1 \mathrm{Xi}+\beta 2 / \mathrm{Xi}+\varepsilon \mathrm{i}$ & Chapagain et al. (2013) \\
\hline M15 & $\mathrm{Yi}=\beta 0+\beta 1 \mathrm{Xi} \beta 2+\varepsilon \mathrm{i}$ & Sharma (2011) \\
\hline M16 & $\mathrm{Yi}=\beta 0+\mathrm{Xi}(\beta 1+\beta 2 / \mathrm{Xi})+\varepsilon \mathrm{i}$ & Chapagain et al. (2013) \\
\hline M17 & $\mathrm{Yi}=\beta 0 \mathrm{Xi}(\beta 1+\beta 2 \mathrm{Xi})+\varepsilon \mathrm{i}$ & Sharma (2006) \\
\hline
\end{tabular}

Note: $y i$ = biomass of individual $i(g), x i=$ explanatory variable for juvenile $i$ [eight explanatory variable alternatives such as (1) D; (2) D2; (3) $D H$; (4) $D 2 H$; (5) $\rho D$; (6) $\rho D 2$; (7) $\rho \mathrm{DH}$; and (8) $\rho \mathrm{D} 2 \mathrm{H}$ were considered, and eight model categories were defined accordingly]; $D i=$ diameter of juvenile $i$ at above $10 \mathrm{~cm}$ from ground $(\mathrm{cm}) ; \mathrm{H} i=$ height of juvenile $i(\mathrm{~m})$; $\rho=$ wood density of juvenile $i(\mathrm{gcm}-3)$, and $b 1, b 2, b 3=$ parameters to be estimated, and $\varepsilon i$ = unexplained error, which was assumed to be independent and normally distributed with zero mean and constant variance.

Table 3: Fit statistics and parameter estimates of the best model of each model category (see definition of model category in Table 2)

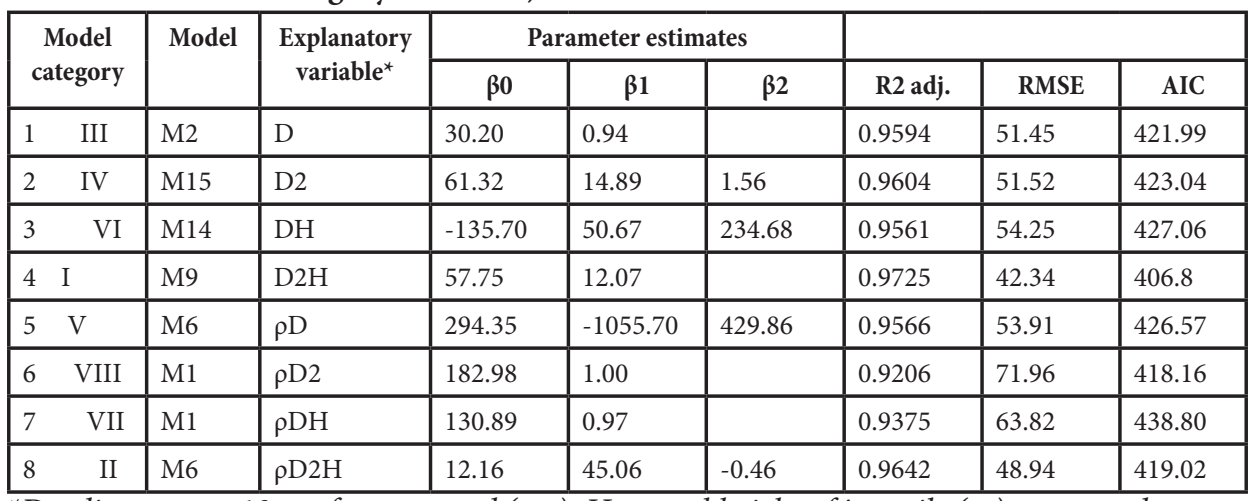

${ }^{*} D=$ diameter at $10 \mathrm{~cm}$ from ground $(\mathrm{cm}) ; H=$ total height of juvenile $(\mathrm{m}) ; \rho=$ wood density of juvenile (gcm-3); all other symbols are the same as defined in Table 2, Eq. 2, and section of modelling approach. 


\section{APPENDIX IV: FIGURES}

Figure 1: Location of study site

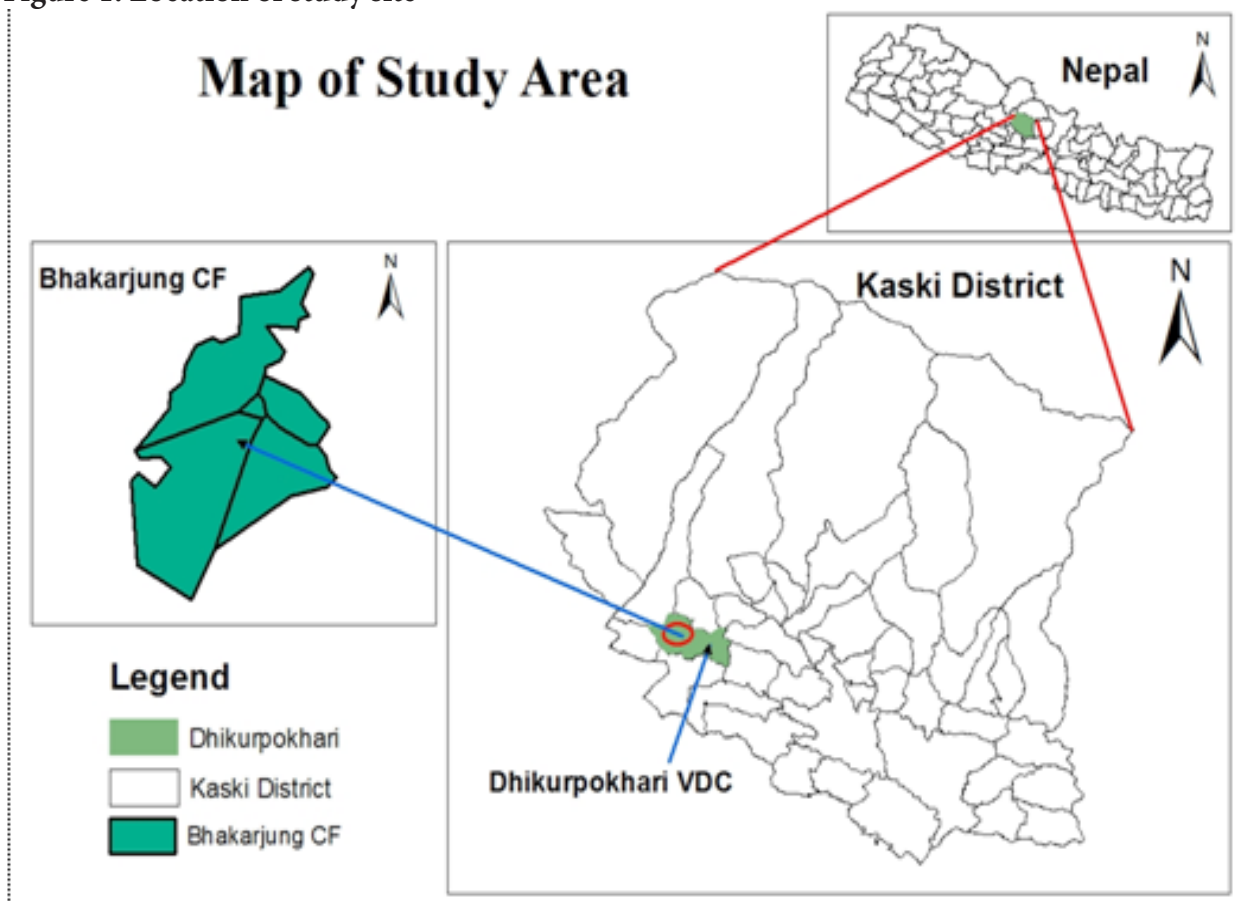

Figure 2: Residual vs Fitted value

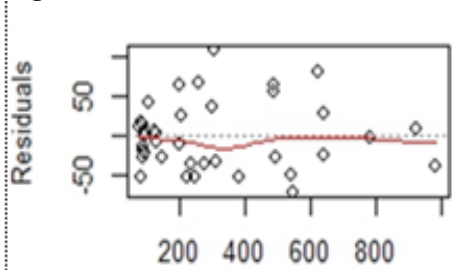

M9 Category fourth

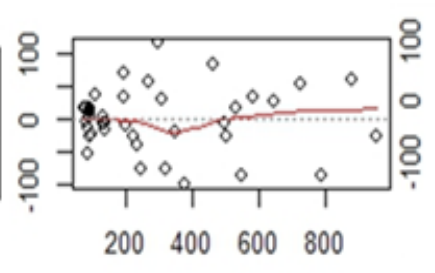

Fitted values

M6 Category Eighth

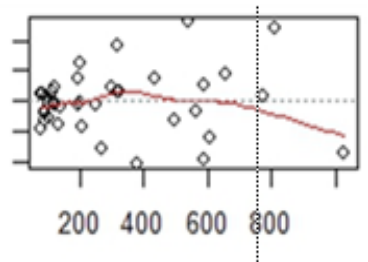

M2 Categogly first

Figure 3: Scale location

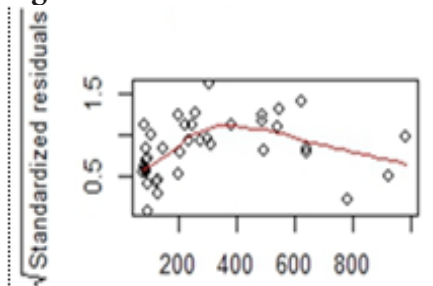

M9 Category fourth

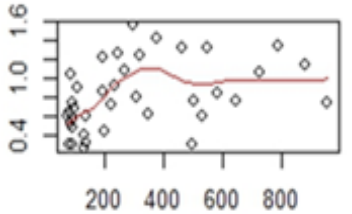

Fitted values

M6 Category Eighth

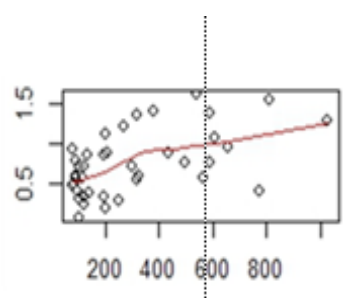

M2 Category first 
Figure 4. Normal Quantile-Quantile plot

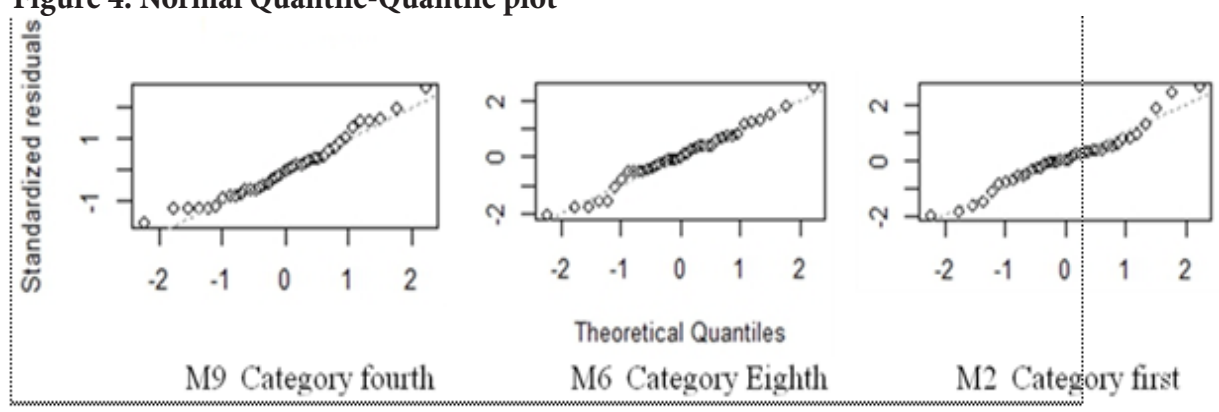

\section{ABOUT THE AUTHORS}

Shes Kanta Bhandari, a master's degree in Forest Science from Dr. Yashwant Singh Parmar University of Horticulture and Forestry, Solan, India, is working as Lecturer at Institute of Forestry, Tribhuvan University Nepal. He teaches Forest Biometrics and Forest Mensuration at University. He has already been involved in several short term project related to forest measurement, biomass and carbon measurement, forest growth modeling etc and published related papers. Prior to this Mr. Bhandari worked as Forest based enterprise development officer at National Entrepreneurship Development Center. Email: shesu15@yahoo.com

Himlal Neupane, a master's degree in Forest Science from Institute of Forestry, Tribhuvan University Nepal, is as Forest Officer at Department of Forest, government of Nepal. He leads forest conservation and management programs. He has more than 15 years of experience in forest conservation and management related work. 